\title{
Intercultural Management in Culturally Diverse Classrooms
}

\author{
Xiaoli Jiang ${ }^{1}$ \\ ${ }^{1}$ Federation University, Australia \\ Correspondence: Xiaoli Jiang, Federation University, Australia. \\ Received: March 23, 2018 \\ Accepted: April 13, 2018 \\ Online Published: April 25, 2018 \\ doi:10.20849/aes.v3i2.374 \\ URL: https://doi.org/10.20849/aes.v3i2.374
}

\begin{abstract}
Globalisation and internationalisation have brought culturally diverse classrooms into universities and schools worldwide. There are increasing opportunities for culturally diverse teachers and students to interact and learn from each other. This paper investigates the changes that occur when classrooms are managed by teachers with different cultural backgrounds from that of their students, utilising observations and interviews. The research indicates that when people from both collective and individualist cultures are in the same classroom, the different dynamics require adjustments from at least one cultural group to achieve desirable learning outcomes, in particular from the teacher. This is largely due to, in individualistic and collective cultures, teachers having different roles associated with their respective power structure and social hierarchy caused by various ways of establishing and maintaining individual self-esteem and perceiving self in relation to others. It would appear that the changes are engineered by a teacher's desire to allow students to learn more effectively and teachers' belief as to what are effective teaching and learning strategies. However, the changes are also accompanied by many challenges and personal growth on the part of the teachers. Bridging cultural differences should never been taken for granted. Should teachers reflect deeply and adjust to changes in classroom culture, the learning and teaching experiences can be both enriching and enlightening. Intellectual challenges and reflections on different home and host cultural assumptions are required when managing students who are from dissimilar cultural backgrounds.
\end{abstract}

Keywords: intercultural management, collective and individualistic cultures, classroom culture

\section{Introduction}

There are marked differences between East and West in learning and teaching practices. From a pedagogy perspective, Eastern education often emphasises conformity, discipline, behaviour control and academic achievement (Rao, Ng \& Pearson 2010). A teacher directed approach and direct instruction on subject teaching are the predominant teaching philosophy and strategy. Content based learning and learning through practicing are the main ways of learning. Whole class teaching and teacher directed activities are the main forms of classroom organisation and activities, normally with all students involved in the same activity (Pearson \& Rao 2004, cited in Rao, Ng \& Pearson 2010). In contrast, Western education emphasises student's individuality and initiative via student centred learning and integrated teaching. Learning approaches are inquiry based and learning through doing. Student initiated and process oriented activities play a vital role in teaching and learning activities (Rao, Ng \& Pearson 2010). As a result classrooms in different cultures are often managed very differently. In collective societies, teachers are perceived as gurus and treated with respect. Teachers have ultimate power in the classroom and student obedience is the norm. Students are not allowed to question teachers and any interruptive behaviours in classrooms are discouraged and often punished (Jiang 2016). However, in Western university classrooms, students and teachers are largely equals. Teachers do not automatically receive respect, but need to earn it. Students often question or even argue their points against that of teachers. Contrary to Eastern classroom culture, students are the people who need to be treated with respect (Jiang 2016).

In the context of these differences, how do teachers and students adjust to changes if in the same classroom the teacher and students have completely different cultural backgrounds and expectations? How do they accommodate the classroom cultural differences and work together? This research paper is aimed to investigate this issue.

\section{Method}

This research utilised multiple approaches to collect relevant data. These include interviews and observations in both Australia and China. 


\subsection{Interviews}

Six lecturers with Asian backgrounds, including four Chinese, one Indian and one Japanese, teaching in Australian universities were interviewed. There were two males and four females. The six interviewees migrated to Western countries between 11 and 25 years ago and have taught between 10 and 23 years in Western education system, including Australia and New Zealand. One also studied in the USA. Two interviewees have a Ph.D. degree, four have a Master's degree. Four interviewees have a continuing position and two were on a contract.

The selection of interviewees was based on their availability. In Australian universities, the number of Asian scholars holding an academic position is very limited. The recruitment of 6 Asian scholars for interview was quite difficult. Limitations on ethnic backgrounds are also obvious. However, the interviewees include 3 different Asian ethnic backgrounds, both genders, different levels of education attainment and difference in length of working life. The ethnic ratio and levels of education attainment of interviewees reflected to a large extent Asian scholars' real workforce situation in an Australian university. Each interview lasted between 40 to 60 minutes and was audio recorded with the consent of the interviewees. The audio records were transcribed and categorised according to several areas of focus. Analysis was applied based on these areas of focus. These are identified below:

- Interviewees' perceptions of differences in students between the interviewees' home countries and those in Australia, focusing on student learning attitudes and ways they learn;

- Interviewees' approaches to teaching and assessments, particularly those that differ from that of their home countries;

- The level of professional satisfaction, challenges and reflections of their teaching in Australia and New Zealand.

The interview sessions were recorded with their consent.

\subsection{Observations}

Six teaching practice classes of three Australian student teachers, one male and two females, in China and two classes of one Asian lecturer (female) in Australia were observed. Notes and photos were taken with teachers' consent. Each class lasted between 45-110 minutes. The student numbers in the classes in China were between 45 and 55. The student numbers in Australia were approximately between 23 (tutorial) and 80 (Lecture). The foci of the class observations were: organization of the classes, teacher's teaching approaches/behaviours, technologies and questions used by the teachers, student response to teachers' teaching instructions/questions, student learning activities and class atmosphere.

Class observation is an effective approach to gather information re what happens in classrooms. It can provide valuable information re teaching and learning activities, teacher and student behaviours and their cultural differences. However, class observations are time consuming and gaining consent of the teaching staff is not always easy. Nevertheless, because of the limitations/difficulties, only 6 classes were observed. It was enough to gain an insight to understanding the teaching and learning behaviours of an Asian scholar and three Australian student teachers.

\subsection{Justification of Research Methods.}

The research methods used in this study are qualitative in nature. Interview has an advantage of obtaining a better understanding of human behaviours, intensions and reasons. It helps readers to gain insight into teacher and student behaviours (Lakomski, 1987). Class observations reveal activities and facts of the classes. These teaching and learning activities are comparable between different teachers and provide valuable teaching and learning insight to the readers. A combination of the two qualitative methods can be more fruitful of insights Gage, 1989), and create a better understanding of culturally different teaching and learning behaviours.

\section{Results and Discussion}

\subsection{Perceptions of Asian Background Lecturers on Differences in Students Between Their Home Countries and Those in Australia, Especially Regarding Student Learning Attitudes and the Ways They Learn}

According to the Asian background lecturers, most students in their home countries work hard and make a full commitment to their studies. In contrast, Australian and New Zealand students appear to have many other things going on in their lives, such as work. They do not fully focus on their studies. However, if they are interested in the subject of their studies, they could be highly motivated and work hard. At the same time two Chinese background lecturers perceive many Chinese students as lazy, don't work unless they are pushed. By comparison they believe Australian students are more self-motivated. 
All interviewees consider that the students of their home countries lack skills in critical thinking, essay writing and oral presentation because of a lack of practice/training in their education. However, they do well in tests and exams because these are the predominant assessment methods in their education.

In terms of obeying rules, Asian lecturers believe that the students in their home countries are good at obeying rules when it comes to class attendance. However, many Chinese students often use their phones while in class. The Australian and New Zealand students obey rules well when in classes, however miss classes more often than their Asian counterparts.

All these differences come from the differences in their cultures and education experiences. The Australian and New Zealand students consider themselves as equals with their lecturers and they have freedom to choose as to whether they come to class and continue their studies. Asian students normally don't have this choice. As a result of the differences the Asian lecturers have changed their teaching approach to manage Australian and New Zealand students according to their cultures. For example, some interviewees articulated:

"Here you need to respect the students and create an inclusive learning environment. You cannot force anything on anybody. In China, the teacher tells you do this and that. You have to obey."

"In Australia if you want to say things, you have to really say it in a friendly, diplomatic way, not offending anyone. There are a lot of laws and regulations and you don't want to get yourself into a lot of trouble. You really have to apply a different approach."

"In Japan, students are quite polite and listen to you even if your speech is a bit boring. In Australia students have the right to choose what they want to study and when they are in the classroom. When they are interested in the subject they will listen to you."

"In Japan, teachers have a right to say please leave the theatre, or please answer the phone outside etc. Here I find if I say that, the student may say I am expecting a call from my work, if I don't answer the phone, I may be placed at a different time or not get work this weekend-more students will argue back here in Australia. In Japan students just obey you. Australian students are independent and have to work to support themselves. So it is OK if they do that. But in Japan it is a common knowledge that students should not do that. Whatever happens, the university is always right. If class starts at 8:30 and finish at 10:00 you cannot miss any part of the class. Here students may say I need to drop off my kid, the earliest I can come is 9:00. It is accepted."

"For Australian students you treat them as adults and efficient leaners, use more equal and respectful way."

According to past research one of the most challenging issues for a teacher from a collective culture is the relationships between teacher and students when they encounter students from an individualistic background (Jiang 2016). In collective societies everyone has his/her own rightful place, together with a certain level of power according to his/her role in the family, workplace, community and society. A high power distance and clear hierarchy is explicit. Hierarchy means existential inequality (Hofstede 2001, 98). Teachers in many collective societies are highly respected. For example, in Confucian cultures, teachers are treated as parents. There is a Teacher's Day (10th September) in China to show respect to those who are educating the younger generations. In Hindu cultures, teachers/academics belong to the highest caste, above kings and warriors. The high respect ensures teachers' prestige and power in society and over the young people in classrooms. A teacher has great power to tell students what to do and students must follow the orders. Any misbehaviours would be condemned by the teacher, principal, fellow students and even parents of the misbehaving students. A punishment often follows. Teachers become accustomed to their conforming behaviour pattern and exercise great power or control over students. This explains the fundamental differences in cultural values that guide different learning and teaching between East and West and underline the challenges that teachers with a collective background may face in individualistic culture oriented classrooms (Jiang 2016).

However, in Western university classrooms, students and teachers are largely equals. Teachers do not automatically receive respect, but need to earn it. Students often question or even argue their points against that of teachers. Contrary to Eastern classroom culture, students are the people who need to be treated with respect (Jiang 2016).

It would appear, the six university lecturers with Asian backgrounds were all well aware the cultural differences and made changes accordingly. They treated students as equals and with respect. However, this is not the case in their home countries. These teachers have been living in the West and teaching for at least 10 years. The years of culture observation, learning and practice have made them adapt to local culture and understand that respect and equality are the key in managing their relationship with students.

However, this adaptation required both time and internal struggles within. For example, one Chinese background 
lecturer recalled: "Initially I was not use to student questions challenging some of my views, especially when discussing political issues regarding China." "It took a lot of time to work this out. It is a process to understand yourself in relation to others, especially students. Initially it was self-threatening indeed. You felt you had lost face or self-esteem in front of so many students. But I now feel quite comfortable to invite student opinions and discussions in classrooms." It would appear that the Asian lecturers have realised that the respect embedded in the teaching position that they used to receive in their home country is no longer a given entitlement. Some of the sanctioned bad behaviours are no long considered as bad. The rules have changed in terms of good and bad, right and wrong. This has caused confusion, frustration and self-doubt. Individual adaptation is clearly required to handle "challenging" behavioural patterns of students that associate with individualistic cultural values and beliefs such as equality and low power distance. It is also a journey of strengthening lecturers' self-esteem and the development of a new perception of a different relationship between lecturer and students in the West. It is clear that the Asian lecturers have made a cultural transition to more individualism orientated education and class management using more equality rules between themselves and the students (Gudykunst 2003).

Provide dates defining the periods of recruitment and follow-up and the pnmary sources of the potential subjects, where appropriate. If these dates differ by group, provide the values for each group.

\subsection{Changes in Classroom Practice and the Reasons for the Changes Made by Asian Background Lecturers}

In the context of different student population, the Asian lecturers appear to have dramatically changed their teaching practices in managing different classrooms from their own home countries. They use Western ways of teaching to engage students, make their teaching highly interactive, student learning inquiry based and process orientated. For example, a Chinese lecturer introduced her methods that are different from what she used in China:

"In China, you just feed students. Here you teach them the way as individuals. You give them the guideline but it is up to each individual what they want to do. It was all blackboard and notes in China. But here is about PowerPoint, video and audio equipment. It is more efficient. The amount of information you can teach now is huge. I use a lot of YouTube to make class fun. I don't like my lectures to be boring. My lectures are all fun. We have student involvement in the lectures. I design a lot of small case studies and organise students into groups and discussions, very different from China. Chinese students really did not have any classroom involvement, all $2-3$ hours were the teacher talking. There was no interaction between teacher and students."

When asked how she learned these different methods, she replied: "I learned this through my experience when I did my MBA and a Certificate for Teaching. I watched as my colleagues' teaching techniques. It is a far better approach."

The Japanese lecturer talked about his changes: "In Japan I would be give students more important information as much as possible. Here I give them things that are more interesting, or teaching things that are more enjoyable. For example, learning Kanji is the hardest learning task. In Japan you just tell students to write 100 times of one kanji to memorise it. Here students can't do 100 times. I learn how Chinese characters were created in history, so I self-taught Chinese character history and told the students stories on each Kanji. Students are happy to learn that way. I spend 1 minute to explain each Kanji, the results are better. They love some of the characters and pretend to be them. They speak Japanese like the character. This is one of the teaching methods I use. I changed my way of teaching because students here wouldn't write 100 time for one Kanji. Keen students may write 10 time to memorise it."

Another Chinese lecturer articulated: "I have changed my teaching methods a lot... I have gone through the stage that I know what students like and dislike, and avoid the negative applications. Some lectures in China are really boring, not much hands on experiences and very little engagement to students. So I try to avoid those things and try to prepare lessons well. I don't recite the things, but build in some funny stories and experiences. I make my lessons as interesting as possible. When it comes to delivery, I assess the class atmosphere. If students are tired, don't try to push through straight away. I may design some alternative activities, use different formats to achieve the same thing. I use PowerPoint, YouTube and videos, but don't overdo it as students nowadays can watch YouTube and videos outside their class. So use them at appropriate times."

A Chinese lecturer teaching in IT expressed his opinions: "There are two completely different course structures between the two countries, so the teaching methods have to change. Teaching and assessment methods are all different. So I change it according to the requirement here. If they are practice related, you will do it. In China there is not much homework. Here there is a lot." 
"I cannot remember how we achieved the objectives without homework in China. But there are lot of ordinary teaching practices in China (Hulong shi)."

"In India there are no tutorials, just lecturers who come to give lectures and go. Students just remember it. Exams are at the universities, not a lot of engagement.... Here we engage students pretty well so I have a very good relationship with each student. But a relationship is not possible if you have 100 students in your class. There were too many students in India. I did not know all of them. So the relationship was really hard. I think learning happens when there is a relationship between teacher and students."

It would appear all lecturers interviewed made radical changes in the context of the western classroom to accommodate student needs. When asked why and what has influenced the changes in their teaching one lecturer answered: "It is about understanding the context in which you teach. So if you don't get the response you want, you have to change the way you teach. If students don't understand, you have to put it in a way that they understand. I just build on it."

"I reflect a lot. When I finish a class I always reflect what has worked and what has not. When I prepare for classes I know this might or might not work. I take a risk. If it doesn't work I either modify or discard." ... "I learn from my mistakes and from the managers how they want me to teach. I saw how the managers teach and noticed how they talked to students and how they wanted us to teach."

She further explained: "I did study in IT and MBA, also a Certificate in Teaching for adults to get into teaching in TAFE. A social science degree in career development. In those studies, I learned how they teach. The certificate of teaching is the best training program and I learned about teaching methods and culture. That helped me the most."

The Japanese lecturer recalled: "I taught in Australian primary and high school for 2 years. I learnt a lot from that, from school teachers." "In Japan all children are very quiet, it is easy to talk about important things. Here you have to make topics interesting to attract students. What I learn here for young children prep and year 1 you need to change topic every 2 to 5 minutes. If the topic is not interesting or too simple students get bored. So I had to prepare 10 tasks for one grade. They cannot even colour things for more than 10 minutes. So I get them to stand up to play Japanese games with hands and fingers, then change to something again. It was only 40 minutes. But for the first week this 40 minutes teaching of prep and grade one, it was a very confusing thing. I did not know what to do. I had to ask the classroom teacher what is required to teach these students. I did not have any Australian teacher training and went straight into primary school classes after my Master by research degree studies. For the first week my primary school class preparation was not appropriate for Australian students... I watched other school teachers and learned. But it was very hard to teach these classes."

Another lecturer articulated: "I received my tertiary education graduate certificates in 2002 and learned some teaching techniques there. Also I think teaching is a skill. I learned a lot and it gives me a good theoretical training, assessment design and delivery. The other thing is you learn by your experience from years of education in different cultures. You know which way is more effective. I think we all have the tendency to reflect. How we did well in one environment, in one course and the reason why we like that lecturer. You try to imitate them. You try to learn just to be one of them. I believe teaching is not just teaching the knowledge, it is who you are and what you do."

A Chinese background scholar talked: "I learn the different ways of communication based on different people through my life, my business work experiences when you handle your clients. When you negotiate you know sometimes you need to be tough, but sometimes have to be flexible. So when you handle different students it is just years of accumulation and it comes out."

Another Chinese lecturer stated: "When communicating with students I treat them as equals, not talking down to them. In China this is considered to be too nice. Students may take advantage of you. But here, you must be nice, not only superficially, but internally. You need to love the students and show your sincerity."

The IT lecturer said: "I made change according to the course requirement and watched other people's teaching. Teaching is simple, if you use your brain a bit you will be OK. Chinese are not stupid. I asked other lecturers if I could watch their classes. They agreed."

He also added: "When I first taught I took a long time to prepare for my classes mainly because my English was no good. You needed to get English right. A lot of vocabularies you need to pronounce them clearly. If it was in Chinese, you just pick it up, have a look and talk for 2-3 hours without a problem. But in English you need to let students understand your lecture and be accurate in pronunciation. It is very different." 
It would appear all Asian background lecturers have initiated fundamental changes through reflections and studies with an aim to adapt to local Australian or New Zealand classroom cultures - Western classroom culture. They understand that in a Western culture dominated society they need to adjust their way of management of classes to fulfil student needs. Sometimes it can be hard and confusing as indicated by the Japanese lecturer. As a minority cultural group, Asian lecturers have realised that changes by themselves are necessary to achieve desirable learning outcomes and to sustain their own teaching position. In summary, the major changes Asian lecturers undertook were in several areas:

- Making learning/teaching content interesting as a part of recognition of student learning background.

- Learning through doing via carefully designed class activities and homework etc.

- Treating students as equals in the lower power distance context.

The major reasons for the changes were:

- Better understanding of the students they teach. The students the Asian lecturers teach in Australia and New Zealand are very different from those in their home countries. As a result, they must change to adapt to student needs.

- Recognition of Western style of teaching is a better way for improved learning. During the interviews, many Asian lecturers clearly expressed that the teaching in their home country was boring and ineffective. This opinion has been built into their value system and guided their actions.

- The Western education the Asian lecturers have received and the cultural environment they are living in. The Western culture and classroom environment have facilitated their cultural learning and adaptation. Most of the six Asian lecturers learnt Western ways of teaching through their education in Australia or the USA and from their colleagues. There was a strong tendency of cultural learning on the part of Asian lecturers. They have reflected much on the differences between their home and host classroom cultures. Making their teaching adapt to the host country student and institutional culture is their main motivation. They are very rational to accept the challenges, and highly motivated to make the changes. No one made any complaints even though the changes did not come easy. All this indicates the adaptation to the host culture and work environment has been highly successful for these migrant academics. According to Berry, Kim, Mondi and Mok $(1987,498)$ migrants who have a higher level of education, their acculturation attitude/motives - voluntariness of contact, prior knowledge of the new language, previous cross-cultural experience - can contribute to migrants' adaptations to the host society. This research further suggests that the Asian interviewees who possess these attributes have made successful adaptations to their work in the host country.

\subsection{Challenges the Asian Background Lecturers Have Faced}

According to the Asian lecturers their teaching in classroom and work may not be as smooth as it first appeared. When the lecturers were asked about the challenges they faced in their teaching, most talked about the cultural and language barriers they encountered.

"Language is a barrier to me, e.g. my writing skills. I sometimes get my husband or son to check my writing. I have done well, but you never ever reach that high level needed for an academic. When my students talk very fast I still miss $5 \%$. It is not your first language."

"The culture part is not too bad because I have worked it out. Initially I had a lot of problems, a lot of expectations. It is the culture here that they are full of themselves and there is nothing wrong with it. I am learning that too and doing it.... I am changing, but it is very hard."

The Japanese lecturer believed: "Communication skills is the first challenge because English is not my native language, so I have to improve my English. For example, in my lectures I have to speak clearly to Australian students and learn the way to clarify and summarise difficult contents in a short speech. I could not speak English when I first came here. I did English but my pronunciation was terrible, like Japanese pronunciation. Language was the biggest challenge."

One Chinese lecturer teaching in business articulated: "The challenges are the teaching environment is such that you have to constantly learn new things and keep up with it. Knowledge structure in business changed after the GFC, you have to update and change."

The Chinese IT lecturer: "English is the only one, but cannot be counted as a challenge. It is a handicap and need practice. There are no challenges re peer relationships and student management. It is all about communication, respect for each other. If you respect students, they will respect you." 
The Indian lecturer: "New Zealand has a bi cultural system. It stopped me from going straight ahead and doing what I think. You have to pull along all the people, you have to get the bi cultural, the Maori people as well to agree what you are doing and to make sure you are doing the right thing. You are in a team and that will curb it. You have peer pressure. They say that is not the right thing and you can't do it. In Australia I felt isolated when I first came, no one guided me immediately. So you feel a bit lost. I was given a room and then you think what do I do next? And you don't know anybody. I was taken around and introduced at that time. There was very few people during the break. However, this is the Indian change, suddenly you can say what you want to say and do what you want to do. And you think what did I say and did I do the right thing? There is no guide. The boundary is very blurred"

Another Chinese lecturer truly believed that language and the Western style of communication had been the biggest challenges. "I spent so much more time on my writing than anything else. After that I give the draft to my husband for corrections. Every time there are always mistakes, endless. You think you have been in the country for so many years and using the language every day. Why can't you get everything right? In reality, you just can't. Because it is not your native language. You did not grow up with it."

"Communication is another thing. It took me a long time to learn the English way of subtle and polite expressions and communication. The Chinese style of communication translation is too direct and demanding. But I am good at the English style of communication now. It is easier to master than the linguistic part if you really reflect a lot on your communication."

It would appear that the challenges were mainly language related and culturally associated. In reality, people can learn another culture, even the communication style much easier than a different language. Language is a hardest part of all the adaptations. The finding of this research is consistent with past studies. Past research has identified that acquisition of English as second language is a prolonged and difficult process (Muñoz \& Singleton 2011, 5). Some research suggests that after a certain maturational point the second language learner is no longer capable of attaining native-like levels of proficiency. (Scovel 2000; 2006; and Long 1990; 2007). This explains why all Asian non English native speaking lecturers considered English language to be their biggest challenge in teaching. The fact is as a non-native speaker, even with many years of living, learning and practicing it is still very difficult to fully master the full depth of a second language, the application of linguistic rules and local pronunciation. One Chinese lecturer who had been teaching in Australia for more than 20 years believes that she will never be able to master the full extent of English as a native speaker, especially in writing. She articulated: "The different expressions in a high level of written English requires a high level of native English studies that is very difficult for a non-native to pick up. The non-native speakers just don't have the same feeling about English. They can't ascertain the correctness of their every expression or words. Small mistakes are always difficult to avoid. Beautiful and high level of English expressions are hard to come by because they are not everyday language."

The handicap could result in much more workload in their teaching preparation. Mistakes in English could also challenge their confidence and produce doubt in their self-esteem, because proficiency in the hosting country's language is considered to be the most important alterable factor contributing to both migrants' social and structural integration (Anniste \& Tammaru 2014; Carliner 2000; Dustmann \& Van Soest 2002; Raijman, Semyonov \& Geffen 2015). However, no interviewees mentioned anything re any negative impact of language difficulties on their self-confidence. They just quietly accepted the challenge believing the handicap is a part of their life. It demonstrates their resilience as people and quality as academics to overcome difficulties in an endeavour to be the best they can.

\subsection{Professional Satisfaction Level of the Asian Background Lecturers}

Despite all the challenges and cultural adaptations the Asian lecturers have made, most lecturers were happy about their changes and had a relatively high level of professional satisfaction. When asked if on a scale of 1 to 10 for career satisfaction, how would they score for themselves? They articulated:

"Ballarat gives me the independence which I did not have in NZ. We had very strong leaders from top down. I enjoyed that because I learned so much. Here I am still learning and being independent and creative which was kept from me. Here I have the space to grow. In NZ my score was 6 because there was no growth. In Australia it is 8 - happy, independent and empowering."

One Chinese lecturer gave: " 8 is the score. I am very happy. If I did not have the health issue I would have been getting a full time job. When I was teaching at primary school for 5 years, it would be 5."

The Japanese lecturer reasoned: "I would give a score of 7 because I am still learning, probably there is still 
much to improve. But for job satisfaction and happiness I would give 8.5. Because here students are honest. In Japan, they hide their emotion. So you can't find out if they like your way of teaching or not. But here, it is quite easy for lecturers to know if you are doing the rights thing or not by looking at students' eyes."

A Chinese lecturer in business told the interviewer "I have been very happy in my teaching and have received several awards including the inaugural School of Business Teaching Award and the Vice Chancellor's Citation Award. A couple of days ago on Chinese Teacher's day, I received e-mails from students from Henna, Beijing, Shanghai, wishing me a happy teacher's day. That is something that makes me really satisfied, better than giving me a promotion or something. When it comes teaching I would give myself a 9. However, if including everything else, it comes to recognition, I don't think my bi-lingual skill has been fully recognised. They don't really appreciate that you are bi-lingual."

The IT lecturer had a different view: "I give it 7 for my satisfaction. It is only a teaching job. I don't really like to be a teacher. But there is not a lot choice. So when I need to teach I do and am happy about myself. That is it."

A Chinese lecturer who had won two Australian Awards for University Teaching gave a score of 9. She believed: "If it wasn't organisational issues I would probably give it even higher. I am really pleased that I have learned so much since I arrived in Australia. There has been so much personal growth during this period. It makes me feel that I am capable of doing many things that I had never thought I could before. I am proud of my progress and improvement particular in a second language"

The high level of job satisfaction in the face of challenges may be explained by "flow" theory. Flow theory investigates optimal experiences, including activities which are both highly engaging and motivational. In 'flow', people feel a sense of control, satisfaction, motivation and happiness, as well as enjoyment (Csikszentmihalyi, \& Csikszentmihalyi 1988). The 'flow' experience encompasses a challenging activity that requires specific skills, clear goals, immediate feedback and the paradox of control (Csikszentmihalyi 1992; Csikszentmihalyi 2014).

Every human activity has the potential to become a 'flow' experience providing the activity achieves a good balance between the challenges and an individual's skills. When challenges are approximately equal to skill levels, a person experiences a feeling of enjoyment and involvement - 'flow' (Csikszentmihalyi 1993). Human beings and their self-esteem can grow as a result of their 'flow' experiences. Asian background lecturers' cultural adaptation is no exception. These scholars have good academic and English skills to meet the challenges of teaching in their second language within a different culture. Although the second language is a vast challenge for them, making them feel at times sense of inadequacy, they do work hard to adapt to Western teaching and the learning environment. Their hard work has compensated for their linguistic and cultural shortfalls. They generally handle their teaching and student learning well, some are outstanding. For example, the two time winner of Australian Award for University Teaching is an example of what Asian lecturers can achieve when they put their hearts and minds into their work. She is one of the most popular lecturers in her Faculty.

The Asian lecturers' work ethic have helped them to meet the challenges and some are even seeking more. Their skills have been stretched during this process and personal growth achieved. Consequently self-confidence and self-esteem have been improved. It should be noted these Asian lecturers all came from a hardworking culture background. They are all strong minded people. Their determination to succeed is extraordinary. They have mobilised all their skills to meet the challenges along their teaching journey. It is not a surprise that they have a high level of job satisfaction because this is their own creation.

\subsection{Observations of One Asian Lecturer's Classes}

The observations of a Chinese background lecturer teaching in Australia revealed a story that is similar to the other Asian background lecturers. She has completely changed her teaching practice to accommodate the Western classroom culture. The Chinese lecturer has a high level of qualifications in teaching and is very observant in her daily living and work in Australia. In her classes, she surpassed most Australian teachers in her appropriate usage of PowerPoint presentations and YouTube videos. Her PowerPoint slides are full of visual aids to the content and the provision of stories further explains and complements the lecture concepts. She also extensively involves students via well designed question and answer sessions in lecture time and class activities in tutorial times. All her teaching behaviours and strategies are fully Western pedagogy driven, designed to stimulate student learning via participation.

Students in her classes responded to her teaching strategies and class management very positively. They actively answered all the questions and participated in all class activities. One of the class activities was student presentation of a textbook chapter. Students were required to prepare and teach one chapter to the whole class and generate class involvement during and/or after presentation via interactive activities such as quiz 
competition, $\mathrm{Q}$ and $\mathrm{A}$, games etc. As a result some students organised role plays and conducted many interesting class activities during their presentations. Some used quiz competitions and rewarded their classmates with sweets. The class atmosphere was lively and students were fully involved in learning.

The observations revealed that if Asian lecturers fully embrace Western teaching and learning approaches they could match or even better their local counterparts. This is because Asian lecturers have experienced two cultures and education systems. They have a much broader view of different teaching and learning strategies and normally are able to analysis the advantages and shortcomings of the two. As a result, they plan their teaching and learning design with a full understanding of strengths and weaknesses of the systems. They are often able to select the best options and reduce the impact of the weaknesses. Consequently this has made possible for a migrant lecturer to win multiple Australian Awards for University Teaching using a second language.

\subsection{Partial Changes Adopted by Australian Student Teachers While Teaching in China}

Observation results also identified that the three Australian student teachers in China prepared Australian style of lesson plans. The Australian style of teaching is student centred. Student and teacher interactions are focused and student learning by doing is the predominate approach to manage their classrooms. Therefore, Australian student teachers, with some knowledge of large student numbers $(50+)$ in Chinese classrooms, prepared PowerPoint presentations and personal demonstrations to teach First Aid as a part of student English studies. This topic was requested by the Chinese school. Australian student teachers did not expect Chinese students to learn too many new words in the first aid area. They went through a few very basic words such as "danger", "snake" etc. Most of the words Chinese students already knew. The student teachers did not have any prior knowledge as to what English vocabularies Chinese students have mastered, how many they need to learn and in how short a time period. This was due to the student teachers not being informed and the textbook not provided prior to their arrival. One of the Chinese supervision teachers who observed the classes was concerned because the large number of vocabularies they wanted students to learn were not covered by the Australian student teachers. After the first class, as suggested by the Australian teaching supervisor, the Australian student teachers were provided with the Chinese textbooks. The Australian student teachers started to cover extensively the vocabularies used in the textbook and focused on teaching pronunciations of the vocabularies. They also added student exercises of writing dialogues because the textbook has dialogues.

Initially the activities organised by Australian student teachers in classes were not all compulsory, most Chinese students just sat around and watched. As a result, student teachers changed their strategies and asked each Chinese student to write their own small essays or dialogue on certain topic in class. Due to the difficulty of checking everyone's progress, the student teachers asked the Chinese students who completed their essay to come up to the front and read it. A small gift was provided as a reward. This did improve some students' motivation and desire to write and share.

The student teachers also increased their request of all students to repeat English words after them. This strategy is not heavily used in Australian classrooms. Changing to a teaching strategy like this was because after two classes Australian student teachers realised if they did not ask 50 students all repeat after him/her, students were not going to have opportunity to speak any English terms in the entire 40 minute class. It was just not possible to allow individual student to study at their own pace as they do in Australia due mainly to the sheer number of students in each class.

It was also not expected from the Chinese school teachers' perspective for the Australians to follow the Chinese way of rote learning style of teaching. The Australian student teachers were able to keep their Western teaching style. It was envisaged to complement the Chinese style and work as a taste for Chinese students to experience learning in a Western classroom. This was the main purpose in bringing in the Australian student teachers by the Chinese school. It should be noted that the Australian student teachers were received with a high level of hospitality from the beginning by the school principal, deputy principal, head of English Department and teachers. They were introduced to the whole school of 3000 students in a school assembly with a warm welcome and student applause. They were given very little direction in terms of their teaching and were allocated to classes to teach from the first day. This perhaps perpetuated the Australian student teachers' belief that their Western way of teaching was welcome in Chinese classes.

The highly welcome and accommodating manner expressed by the Chinese school could be explained by China's long history of many attempts of introducing Western education. Western education was first introduced to China in 1818 via the establishment of the first mission school, namely the Anglo-Chinese College (Yu, 2016). Over the last 200 years China has tried to introduce different Western concepts to Chinese education including pedagogy and teaching methods (Sun \& Du, 2008), but achieved little long lasting effect (Zhu 2000; Cui 2009). 
Due mainly to the acceleration of globalization and internationalization in the past 20 years, more and more Western educators have been invited to China to teach, together with their Western teaching methods. These have challenged the traditional Chinese rote learning approach. At the same time, millions of Chinese have travelled overseas to study. It would appear the Chinese education system faces intense competition from the West in recruiting Chinese students. In this context, the Chinese education authority stresses self-confidence in the Chinese education system, teaching approaches and learning focus. They also continuously identify shortcomings of Western education (Gu, Zhu \& Wang, 2017). However, the large number of Chinese students travelling overseas to study and the active recruitment of Western English speaking teachers by Chinese schools and universities have become a statement of the willingness to accept Western education by the Chinese. This research has revealed the real attitudes towards Western education and teachers from school and student perspectives. Clearly over the last two hundred years Chinese education development in learning and teaching approaches has experienced a constant battle between continuation of Confucian education philosophy and new Western education approaches. The struggle continues in the current Chinese education system.

\subsection{Chinese Students Partially Change Their Behaviours to Suit Australian Student Teachers' Cultural Background}

Due to Australian student teachers' western style of teaching such as using word games and presentation of short essays written by Chinese students, Chinese students responded. They participated in the word games very well. Some read their essays to the whole class and obtained a small gift for sharing their writings. Further, the formality of all students standing up to greet the teacher with "Good Morning Teacher" or "Good Afternoon Teacher" when teacher enters the classroom was abandoned. Neither did they say "Goodbye Teacher" when class finished. These hierarchy rituals in China are designed to show respect for teachers and affirm teacher's authority. However, they were not practiced for the Australian student teachers. No one told them not to do the rituals. It was just because there was no command words such as "Class begins" or "Class has finished" from the Australian student teachers in a loud and commanding manner to trigger those actions from the Chinese students. The class atmosphere was relaxed, lacking the normal rigidity of the Chinese classroom. This is not to say that the Chinese students did not respect the Australian student teachers. To the contrary, the Chinese students loved the Australian student teachers. They took photographs with them after every class, surrounded them with a lot of questions and stares. The Australian student teachers demonstrated equality and a down to earth approach to teaching that relaxed the Chinese students. The Chinese students considered the Australians' classes to be unique. Their gentle manner and softly spoken style were different and interesting.

It would appear that the Western style of education was attractive and had some positive impact on Chinese students. This perhaps was because Western education development has had a long history in researching children's needs and effective learning and teaching process, as early as the beginning of the nineteenth century, just after the French Revolution. Learning became more integrated. The design of teaching and learning has considered human nature and physiological bases of perception. It has been more behavior and learning focused (Burridge, 1970). With mass education becoming a reality, the twentieth-century education was affected by the new science of psychology. A child-study movement was initiated. Child-centered learning, and school centered educational procedures began from child-study laboratory. This paved the foundation for the modern era's student centered learning (Bowen, 1981). Successive educational thinkers, scientists and psychologists such as Maria Montessori, John Dewey and William James etc. engineered significant progress in education theory and practice based on scientific research and experiments (Bowen, 1981) that have influenced the modern education today. It is no surprise the Chinese students accommodated the Australian student teachers' teaching style so quickly. It would appear it was the intrinsic value of their teaching approaches and attitudes that attracted Chinese students. Their addressing of individual interests, appealing to self-motivation and exercising equality also affected them.

\section{Conclusion}

This paper has identified that the Asian background lecturers interviewed have successfully navigated through their cultural and linguistic struggles. Their success in adapting to the Western way of teaching and class management has several reasons. Firstly, their positions required them to do so. For example all the requirements of course structure, assessments and delivery need to be set-up according to the Western way of teaching and learning. Without making the changes they simply cannot perform well in this education system. Student feedback would be bad. Their employment position would not be sustainable. As a result they had no choice but to rise to the challenges to fully accommodate the needs of the Western education system and students.

Secondly, most of the Asian lecturers intrinsically were willing to make changes because they believe the 
Western way of teaching and learning is more effective. They also believe they need to make changes according to their students' needs. They recognised that the students in their adopted country are a completely different population from their original home country. The culture change also influences these lecturers to treat their students as equals, not subordinates.

Thirdly, Asian lecturers' high levels of education, skills and hardworking ethic have enabled them to meet challenges that created by communicating in a second language and teaching in a different culture. They have embarked on a rewarding journey in their adopted country by constant personal growth, enhanced self-confidence and a high level of professional satisfaction.

On the other hand, the Australian student teachers in China changed only a small portion of their practices in order to accommodate the Chinese students and their culture. This is mainly because they truly believe the Western way is a better way than that of rote learning in China. Further, although they were briefed as to how Chinese teach, they never had a chance to see it until they arrived in China. However, this style of teaching cannot achieve the learning goal of remembering a large number of English words and sentences as rote learning normally does. But there was little expectation from the Chinese school on this matter because there has been a long history in Chinese education of adopting the Western style of teaching and learning. The employment of Australian student teachers would bring prestige to the school. The Chinese students would have an opportunity to experience the Western style of teaching and teacher behaviours.

This study demonstrates that intercultural management of class activities normally requires a full adaptation by Asian background lecturers to the Western way of teaching, learning and assessment in Western countries. Clearly the Asian lecturers researched are doing it with a high level of self-motivation and job satisfaction. In contrast, the Western student teachers did not manage the culturally different Chinese classroom with a great deal of change. They still largely utilised their Western way of teaching given their teacher training. The study suggests that Western style of teaching and learning are considered by many people to be more effective or acceptable than the traditional Asian way. This view can perhaps be supported by educational research over the past more than 200 years in the West that shows student centred learning to be an effective way to achieve better learning outcomes.

However, the Western style of student centred learning and teaching is normally implemented in a classroom with relatively small student numbers. It would be a great challenge if the same classroom management strategy and teaching style were implemented in a very large classroom with 50-60 students, and when there were examination requirements.

Further, this study was limited to interviewing six Asian scholars and observing a small number of classes. More interviews and prolonged observation of classes is required to investigate Australia student teachers or teachers' teaching and learning activities in Asian countries.

\section{References}

Anniste, K., \& Tammaru, T. (2014). Ethnic Differences in Integration Levels and Return Migration Intentions: A Study of Estonian Migrants in Finland. Demographic Research, 30(13), 377-412. https://doi.org/10.4054/DemRes.2014.30.13

Berry, J., Kim, U., Minde, T., \& Mok, D. (1987). Comparative Studies of Acculturative Stress. International Migration Review, 21(3), 491-511. https://doi.org/10.2307/2546607

Bowen, J. (1981). A history of Western education, the modern West Europe and the new world. London: Methuen.

Burrideg, T. (1970). What happened in education: An introduction to Western education history. Boston: Allyn and Bacon.

Carliner, G. (2000). The Language Ability of US Immigrants: Assimilation and Cohort Effects. International Migration Review, 34(1), 158-182. https://doi.org/10.2307/2676016

Csikszentmihalyi, M. (1992). Flow: The psychology of happiness. London: Rider.

Csikszentmihalyi, M. (1993). The evolving self: A psychology for the third millennium. New York: HarperCollins.

Csikszentmihalyi, M. (2014). Flow and the Foundations of Positive Psychology the Collected Works of Mihaly Csikszentmihalyi. SpringerLink. 
Csikszentmihalyi, M., \& Csikszentmihalyi, I. (1988). Optimal experience: Psychological studies of flow in consciousness. New York: Cambridge University Press. https://doi.org/10.1017/CBO9780511621956

Cui, G. (2009). The Promotion of Western Education Theory in China in the 1920s. Master's dissertation. Taiyuan: Shanxi Normal University. Retrieved July 18, 2017, from http://cdmd.cnki.com.cn/Article/CDMD-10118-2010039579.htm

Dustmann, C., \& Van Soest, A. (2002). Language and the Earnings of Immigrants. Industrial \& Labor Relations Review, 55(3), 473-492. https://doi.org/10.1177/001979390205500305

Gage, N.L. (1989, October). The paradigm wars and their aftermath. Education Researcher, 4-10.

Gu, M., Zhu, Y., \& Wang, D. (2017, March). Where Is the Confidence for Chinese Education?. The Chinese Education. $\quad$ Retrieved July $17, \quad 2017, \quad$ from http://www.moe.gov.cn/jyb_xwfb/s5147/201703/t20170303_298082.html

Gudykunst, W. (2003). Issues in cross-cultural communication research. In W. Gudykunst (Ed.), Cross-cultural Intercultural Communication (pp. 149-161). London: Sage.

Hofstede, G. (2001). Cultures and organizations: Software of the mind. London: McGraw-Hill book.

Jiang, X. (2016). Reflections on Cultural Differences between Individualistic and Collective Societies-Adaptation to Individualism Orientated Learning and Teaching. In K. Coleman \& A. Flood (Eds.), Enabling Reflective Thinking: Reflection and Reflective Practice in Learning and Teaching. Common Ground Publishing Series: Creativity in Learning and Teaching (pp.36-57). Champaign, Illinois: Common Ground.

Lakomski, G. (1987). Case study methodology and the rational management of interaction. Education Management and Administration, 15, 147-157. https://doi.org/10.1177/174114328701500210

Long, M. (1990). Maturational constraints on language development. Studies in Second Language Acquisition, 12(3), 251-285. https://doi.org/10.1017/S0272263100009165

Long, M. (2007). Problems in SLA. Mahwah, NJ: Lawrence Erlbaum Associates.

Muñoz, C., \& Singleton, D. (2011). A critical review of age-related research on L2 ultimate attainment. Language. Teaching, 44(1), 1-35. https://doi.org/10.1017/S0261444810000327

Raijman, R., Semyonov, M., \& Geffen, R. (2015). Language Proficiency among Post-1990 Immigrants in Israel. $\begin{array}{lllll}\text { Journal of Ethnic and Migration Studies, } & \text { 41(8), }\end{array}$ https://doi.org/10.1080/1369183X.2014.982523

Rao, N., Ng, S., \& Pearson, E. (2010). Preschool pedagogy: A fusion of traditional Chinese beliefs and contemporary notions of appropriate practice. In C.K.K. Chan \& N. Rao (Eds.), Revisiting the Chinese learner: Changing contexts, changing education (pp. 255-280). Hong Kong: The University of Hong Kong, Comparative Education Research Centre Springer Academic.

Scovel, T. (2000). A critical review of the Critical Period Hypothesis. Annual Review of Applied Linguistics, 20, 213-223. https://doi.org/10.1017/S0267190500200135

Scovel, T. (2006). Age, acquisition, and accent. In C. Abello-Contesse, R. Chacón Beltrán, M.D. López-Jiménez, \& M.M. Torreblanca-López (Eds.), Age in L2 acquisition and teaching (pp. 31-48). Bern: Peter Lang.

Sun, P., \& Du, C. (2008). History of Chinese Education. Shanghai: Huadong Normal University Publishing House.

Yu, Q. (2016). Chinese Education History. Textbook for Chinese Universities. Online Education, China. Retrieved July 17, 2017, from http://v.dxsbb.com/renwen/1886/\#Introduce

Zhu, Y. (2000). History of Chinese and Western Education. Nanjing: Publishing house of Nanjing University.

\section{Copyrights}

Copyright for this article is retained by the author(s), with first publication rights granted to the journal.

This is an open-access article distributed under the terms and conditions of the Creative Commons Attribution license (http://creativecommons.org/licenses/by/4.0/). 